\title{
GEOMETRIC COMPLEXITY ANALYSIS IN AN INTEGRATIVE TECHNOLOGY EVALUATION MODEL (ITEM) FOR SELECTIVE LASER MELTING (SLM) ${ }^{\#}$
}

\author{
S. Merkt ${ }^{1^{*}}$, C. Hinke ${ }^{2}$, H. Schleifenbaum ${ }^{3} \&$ H. Voswinckel ${ }^{4}$ \\ 1, 2 Department of Laser Technology \\ RWTH Aachen University, Germany \\ ${ }^{1}$ simon.merkt@ilt.fraunhofer.de; ${ }^{2}$ christian. hinke@ilt.fraunhofer. de \\ ${ }^{3}$ Fraunhofer Institute for Laser Technology (ILT), Germany \\ henrich.schleifenbaum@ilt.fraunhofer.de \\ ${ }^{4}$ Institute of Metal Forming (IBF) \\ RWTH Aachen University, Germany \\ voswinckel@ibf.rwth-aachen.de
}

\begin{abstract}
Selective laser melting (SLM) is becoming an economically viable choice for manufacturing complex serial parts. This paper focuses on a geometric complexity analysis as part of the integrative technology evaluation model (ITEM) presented here. In contrast to conventional evaluation methodologies, the ITEM considers interactions between product and process innovations generated by SLM. The evaluation of manufacturing processes that compete with SLM is the main goal of ITEM. The paper includes a complexity analysis of a test part from Festo AG. The paper closes with a discussion of how the expanded design freedom of SLM can be used to improve company operations, and how the complexity analysis presented here can be seen as a starting point for feature-based complexity analysis.
\end{abstract}

\section{OPSOMMING}

Selektiewe lasersmelting word geleidelik 'n gangbare ekonomiese keuse vir die vervaardiging van opeenvolgende komplekse onderdele. Die navorsing is toegespits op die ontleding van meetkundige kompleksiteit as ' $n$ gedeelte van ' $n$ integrerende tegnologiese evalueringsmodel. Gemeet teen konvensionele evalueringsmodelle behandel die genoemde metode interaksies tussen produkte- en prosesinnovasies wat gegenereer word. Die navorsing behandel ' $n$ kompleksiteitsontleding van ' $n$ toetsonderdeel van die firma FESTO AG. Die resultaat toon hoe kompleksiteits-analise gebruik kan word as die vertrekpunt vir eienskapsgebaseerde analise.

\footnotetext{
${ }^{1}$ The author is enrolled for a PhD degree at the RWTH Aachen University.

2 The author is enrolled for a PhD degree at the RWTH Aachen University.

3 The author was enrolled for a PhD degree at the RWTH Aachen University.

${ }^{4}$ The author is enrolled for a PhD degree at the RWTH Aachen University.

* Corresponding author.

\# This article is an extended version of a paper presented at the 2011 RAPDASA conference
} 


\section{INTRODUCTION: STATE-OF-THE-ART / MOTIVATION}

SLM is a manufacturing process that builds up metallic or ceramic parts layer by layer directly from 3D-CAD data [1]. The parts are fabricated from metal or ceramic powders on a substrate. The powder on the substrate is selectively melted by a laser beam according to the sliced CAD model (see Fig. 1). After the first layer is melted, the substrate plate is lowered, and new powder is deposited on top of the first layer. This new layer is selectively melted, and the layers (approximately $50 \mu \mathrm{m}$ ) are metallically bonded. The final component is thus built of many single layers. The density of the parts is about $100 \%$ and the mechanical properties can even beat conventional manufacturing processes such as diecasting [2]. In addition, novel geometries can be generated (the only limitation being the imagination of the designer) and can be used to improve the performance of conventional product designs $[3,4]$.

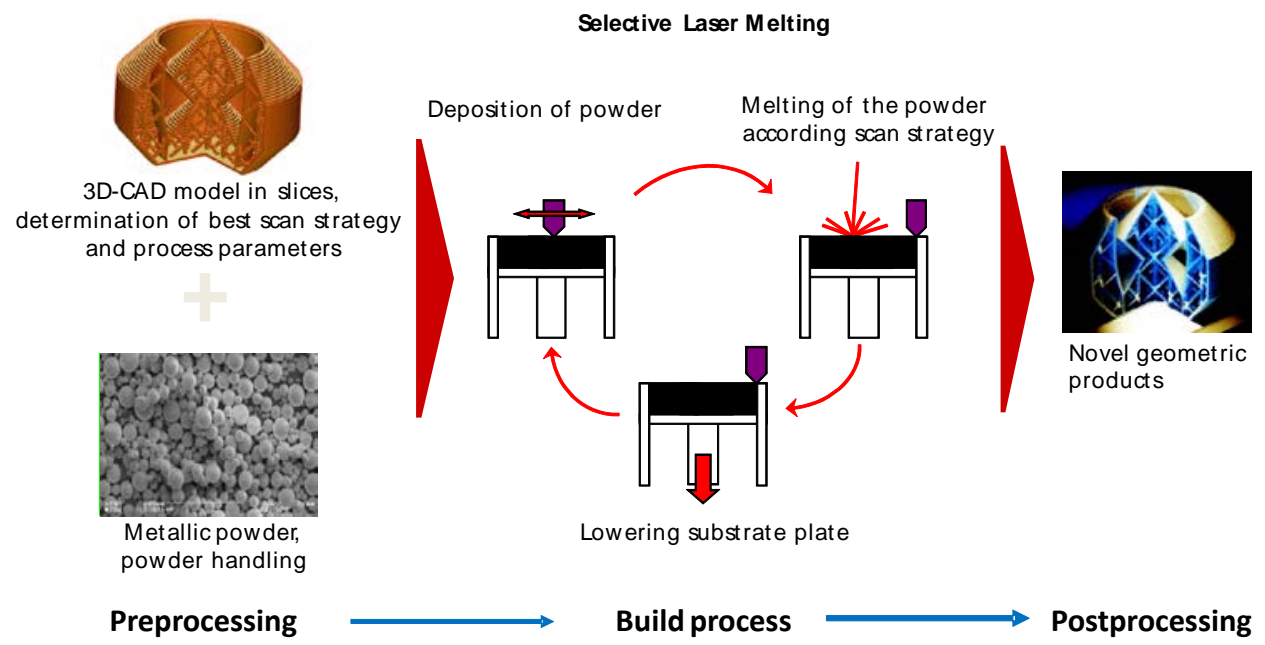

Figure 1: Schematic SLM process

Typical build rates are around $1.2 \mathrm{~mm}^{3} / \mathrm{s}$ and depend on material and quality requirements. To improve the build rate by a factor of ten, the Fraunhofer Institute for Laser Technology (ILT) designed and built an innovative laser. To reach the desired build rate improvement, it investigated increasing the laser power from 200/400 W to $1 \mathrm{~kW}$ (high power selective laser melting), and implementing a new scanning strategy (skin-core strategy) [5].

These process improvements helped to build aluminium parts quickly that are suited for eco-design (due to their low weight and superior mechanical and chemical properties). State-of-the-art build-rates for aluminium $\left(5 \mathrm{~mm}^{3} / \mathrm{s}\right)$ could be improved by a factor of four to five; up to $21 \mathrm{~mm}^{3} / \mathrm{s}$ by using high power selective laser melting (HPSLM) [6].

These improvements resulted in higher process productivity, and enabled the economic production of series components (direct manufacturing) in small batch sizes. SLM can even beat conventional processes if complex products with a high amount of functional integration need to be fabricated [7]. New methods to exploit the potential of SLM for mass customisation are investigated to further enhance the application field. Trends that follow globalisation and the saturation of consumer demand, such as mass customisation and individualisation, will further raise the need for a highly flexible and individualised production. These requirements are seen as one of the big challenges in manufacturing technology [8]. SLM is a suitable solution to facing this challenge by producing highly individualised products at low prices.

Increasing complexity leads to exponentially increasing costs of conventional production technologies for small series production (see Fig. 2). In contrast to conventional production 
technologies, manufacturing costs for additive manufacturing (AM) technologies like SLM do not normally increase with higher geometric complexity.

In some cases, higher geometric complexity leads to higher preprocessing costs of SLM (e.g. platform assembly, backing, scanning strategy, etc.). At the same time, high geometric complexity often means lower build volumes: this decreases the process time for SLM and equalises the additional preprocessing costs.

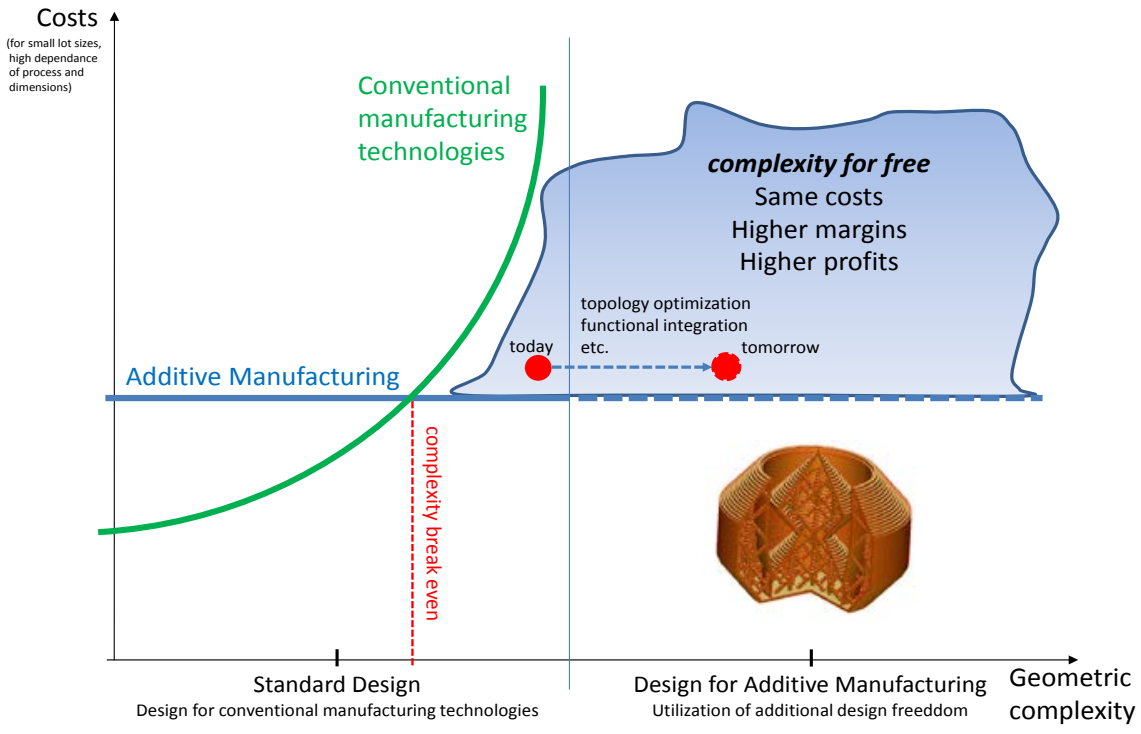

Figure 2: The idea of 'Complexity for Free' according to [9]

For products that exceed a standard design, SLM can be economically superior due to apparent cost drivers of conventional technologies. Functionally-optimised designs ('design for AM') can improve product performance at the same cost. This idea of 'complexity for free', using the additional design freedom of SLM, is shown in Figure 2. Today several applications exceed a certain amount of economical standard design ('complexity breakeven') and are manufactured more economically with SLM. The additional design freedom through SLM could be used for future applications that use geometric complexity to improve product performance at the same costs (see Fig. 2). Furthermore, SLM enables innovative business models through product individualisation because costs are independent of lot size - in contrast with conventional manufacturing processes.

\section{INTEGRATED TECHNOLOGY EVALUATION MODEL (ITEM)}

The general objective when evaluating technologies is to determine the impact of technology decisions on a given valuation standard [9]. Technology evaluation is an important tool for technology management; it supports the selection, planning, controlling, and positioning of technology. Without targeted technology management, it is difficult for companies to succeed when their surroundings change, and to fulfil increasing market/ product requirements. Adaptation to these changes needs to be performed at the technological level. Long-term strategic technology decisions can lead to significant competitive advantages, and build a key point for the future viability of companies.

There are several approaches to general technology evaluation in production that focus on different evaluation criteria. None of them can integrate all the criteria relevant to supporting a comprehensive decision-making process.

None of the decision methods listed by [10] can support the decision-making process if highly innovative manufacturing methods are evaluated because of their focus either on product or process. Highly innovative manufacturing technologies such as SLM have an 
impact on both product and process design at the same time. Most approaches do not cover interactions between product and process innovations [11]. To consider these interactions, an ITEM for SLM will be introduced to extend state-of-the-art decision frameworks (see Fig. 3). Unlike conventional technology evaluation methods, the ITEM matches (among other things) manufacturing process limitations and product requirements, to determine a suitable manufacturing method. The ITEM focuses on the main decision parameters, and helps to ensure systematic planning cycles, as well as parallel design and manufacturing activities, to shorten the development times of new products. Since the process limits are considered inflexible, at least in the short term, the individual product design is of major importance for product development [12].

\section{Level: Product process analysis (technical level)}

- Integrated product process model (PPD-model)

- Matching process limitations and product requirements

- Result: Technical design related ranking of manufacturing processes

\section{Level: Economic analysis (economic level)}

- Product design and manufacturing process considered inflexible

- Economic comparison of manufacturing processes with financial ratios / complexity analysis

- Result: Economic Ranking of manufacturing processes

\section{Level: Economic potential analysis (potential level)}

- Product design and manufacturing process considered flexible

- Innovation analysis to improve product performance

- Cost / benefit ratio as key indicator

- Result: Ranking after redesign

\section{Level: Technology potential analysis (potential level)}

- Portfolio analysis

- Considering of company specific potential and strategy potential

- Result: Company related decision of application technology

Figure 3: Evaluation levels of the integrative technology evaluation model for SLM

In order to use the potential of innovative manufacturing processes, four different levels of the ITEM need to be considered to determine the suitability of manufacturing processes on any specific application (see Fig. 3).

The integrated product process design model (PPD-model) builds the first level of the ITEM, and covers all technically-related decision parameters. Several key indicators are matched with product requirements to determine all technically-suitable manufacturing technologies. On the second level, an economic ranking is determined by comparing manufacturing technologies with financial ratios. A complexity analysis helps to group products into different manufacturing groups to derive first economic assumptions. The product design and manufacturing process is considered flexible in the economic potential analysis on Level 3 of the ITEM. This allows the designer to improve product performance by using the potential of innovative methods and to compare them using a cost/ benefit ratio.

A technology potential analysis ends the evaluation process of the ITEM by considering company-specific manufacturing potentials (e.g. expansion on other products) and strategic possibilities (e.g. mass customisation) that are generated through innovative technologies like SLM. 
After completing all four stages of the ITEM, a decision can be made regarding the most suitable production technologies. The complexity analysis from Level 2 is the focus of this investigation.

\section{GEOMETRIC COMPLEXITY ANALYSIS OF A TEST PART}

Complexity analysis may help to determine the right manufacturing technologies for specific applications. As shown in Figure 4, geometric complexity and lot size are important criteria for the selection of a manufacturing process.

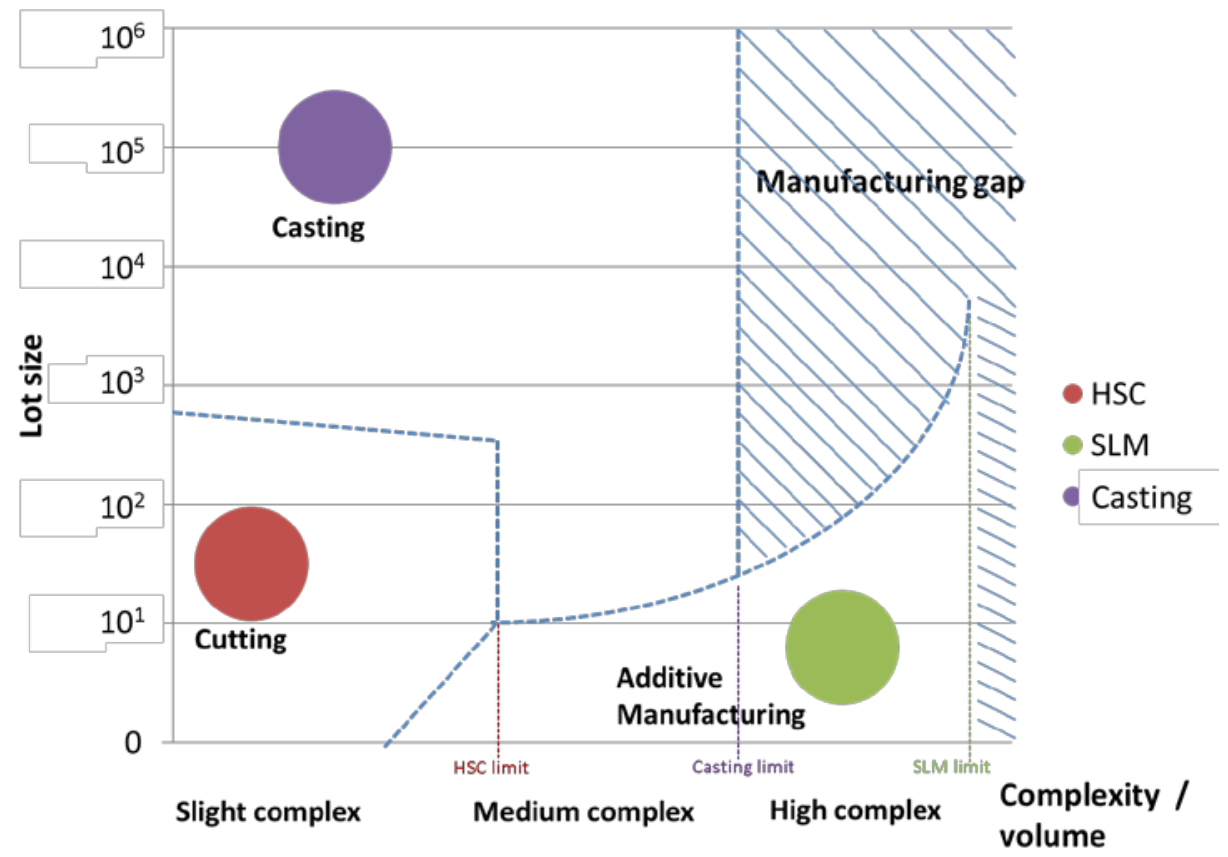

Figure 4: Two-dimensional selection pattern for manufacturing processes [7]

Highly complex products are generally more suitable for SLM because geometric complexity leads to increased costs when conventional technologies are used [7, 13]. Geometric (shape) complexity, for example, increases the manufacturing time (costs) for machined parts due to additional set-ups, the number of tool changes, and the amount of removal volume. High speed cutting (HSC) and casting processes have lower limits in achievable geometric complexity than additive manufacturing technologies like SLM. SLM is not yet applicable to high lot size, for reasons related to productivity. Thus manufacturing gaps exist for highly complex parts as well as for high lot size, and at a certain complexity level even that cannot be achieved by SLM (see Fig. 4).

Based on 3-D CAD models in the STL-format, several ratios can be applied to determine the geometric complexity of a test part from Festo AG (see Fig. 5).

Valentan [14] has introduced ratios to determine geometric complexity based on the STL format. The following ratios are applied to the Festo test part, and compared with a selection of typical machined, cast, and SLM parts:

- Parts volume/ number_of_facets

- Parts volume/ surface area

- Parts volume/ block volume 

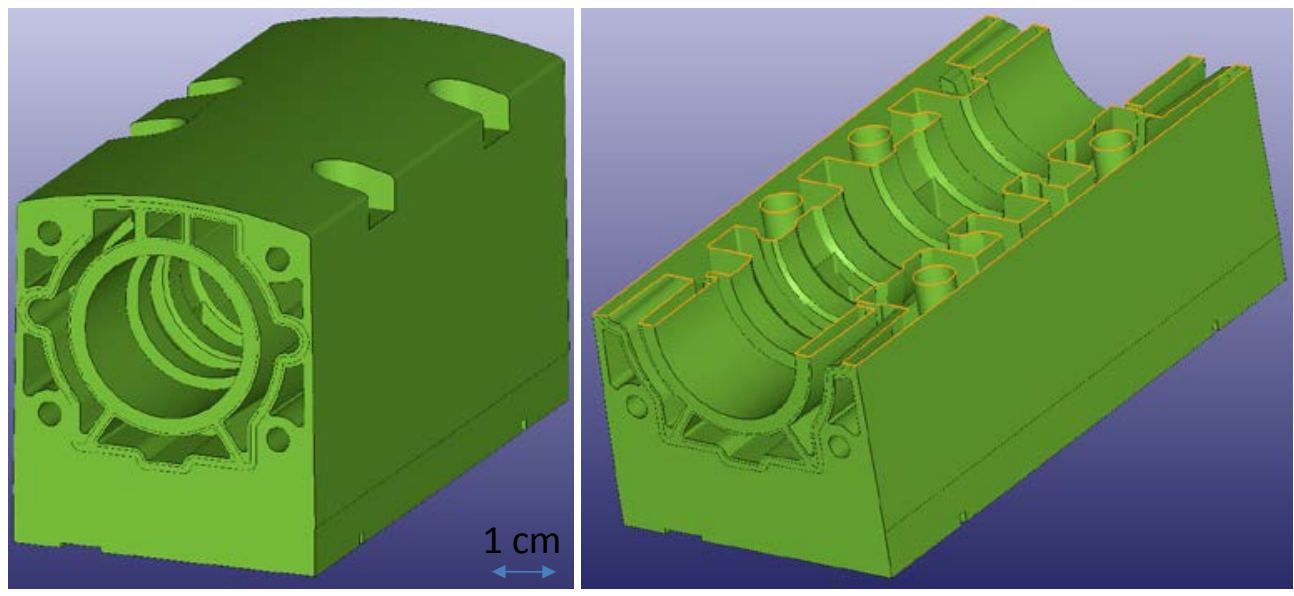

Figure 5: Festo test part

The STL format is a facet-based representation that approximates surface and solid entities only. Difficult surfaces and solids are represented by a high number of facets in the STL format. A low ratio of volume/ number_of facets means high geometric complexity. As shown in Figure 6 , the Festo test part has the second lowest parts volume/ number_of facets ratio. Only typical SLM parts have a lower ratio. Note that the die-cast Festo part has a four-time lower ratio than the average value of the investigated casting parts. This indicates a relatively high geometric complexity of the test part.

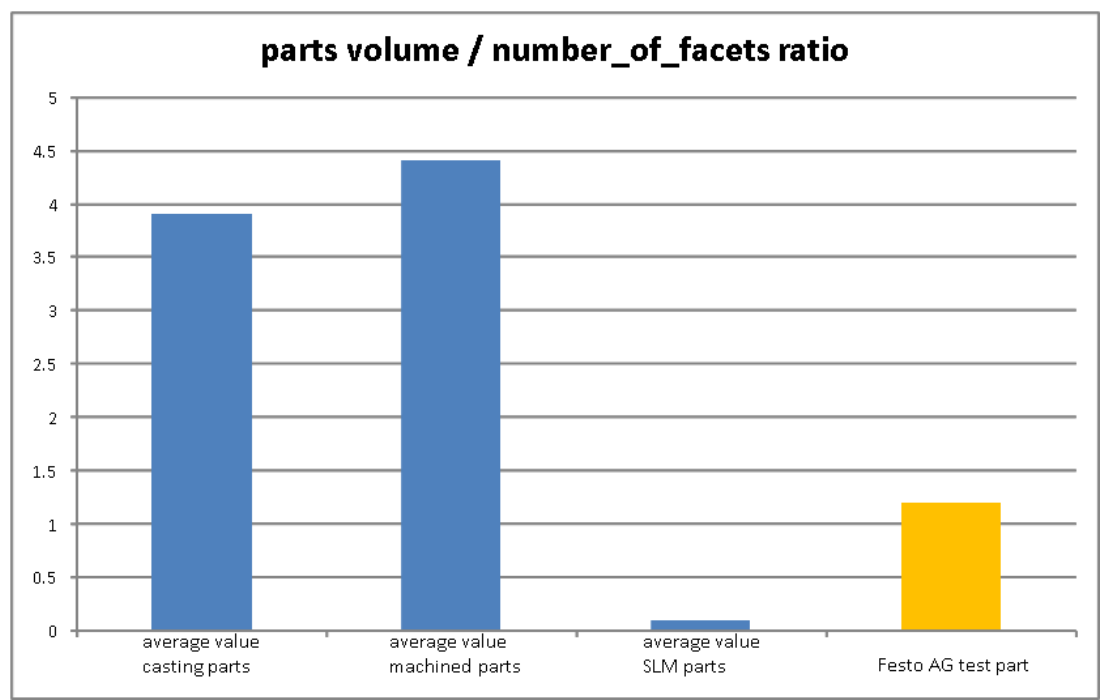

Figure 6: Complexity analysis based on parts volume/number_of_facets ratio

The second ratio that can be used to estimate geometric complexity is parts volume/ surface area. This ratio can differentiate massive parts from parts with a high number of free-form surfaces and curved surfaces [15]. Again, the Festo test part has a lower value than the average reference value of cast and machined parts (see Fig. 7). The average of SLM parts is significantly lower than the value of the Festo test part. In contrast to cast parts that need additional volumes due to design restrictions, almost no additional volume needs to be built up by SLM. In comparison with machined parts, only functional volume is built up by the generative manufacturing process SLM. This leads to extremely low values for parts volume/surface area in comparison with other manufacturing 
techniques. For the Festo test part, parts volume/ surface area ratio still indicates medium high geometric complexity.

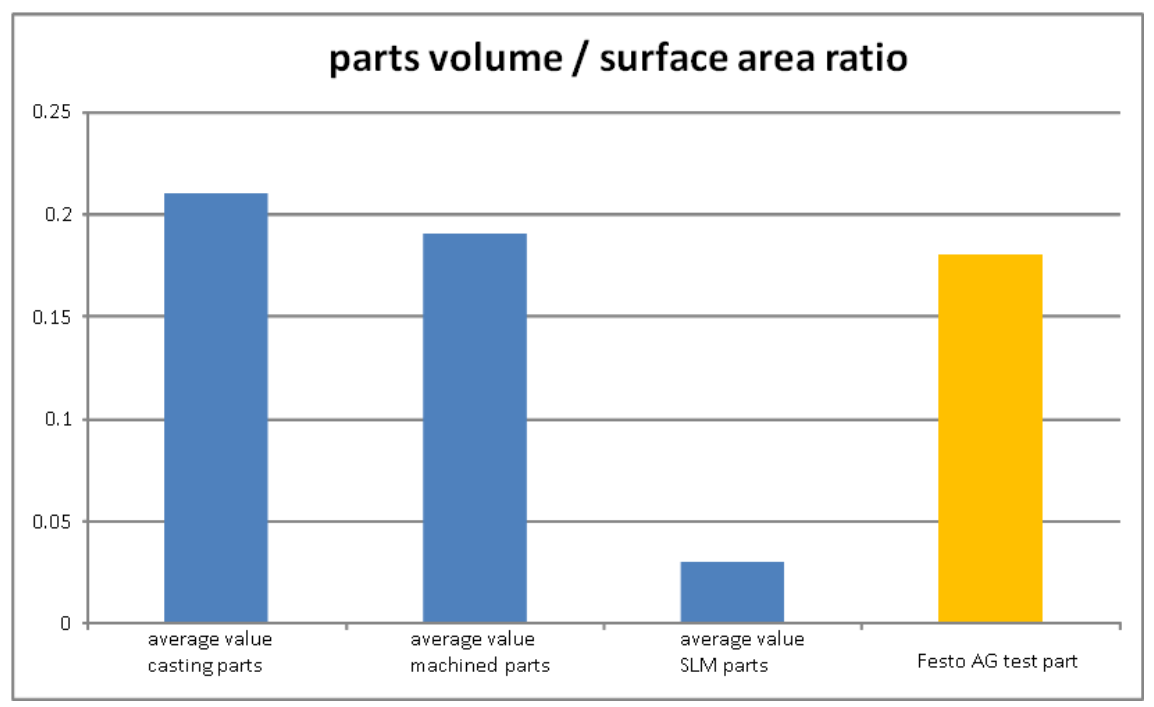

Figure 7: Complexity analysis based on parts volume/surface area ratio

The last ratio for estimating geometric complexity is the parts volume/ block volume ratio. The block volume can be calculated by multiplying the maximum values in the $x-, y-$ and $z-$ directions. Similarly to the ratio of parts volume/surface area, this ratio can be used to differentiate massive parts from complex parts with a high number of free-form surfaces. The Festo test part shows a relatively high value of parts volume/ block volume (see Fig. 8). The high value for parts volume/block volume indicates that the Festo test part is a compact one with a relatively low geometric complexity.

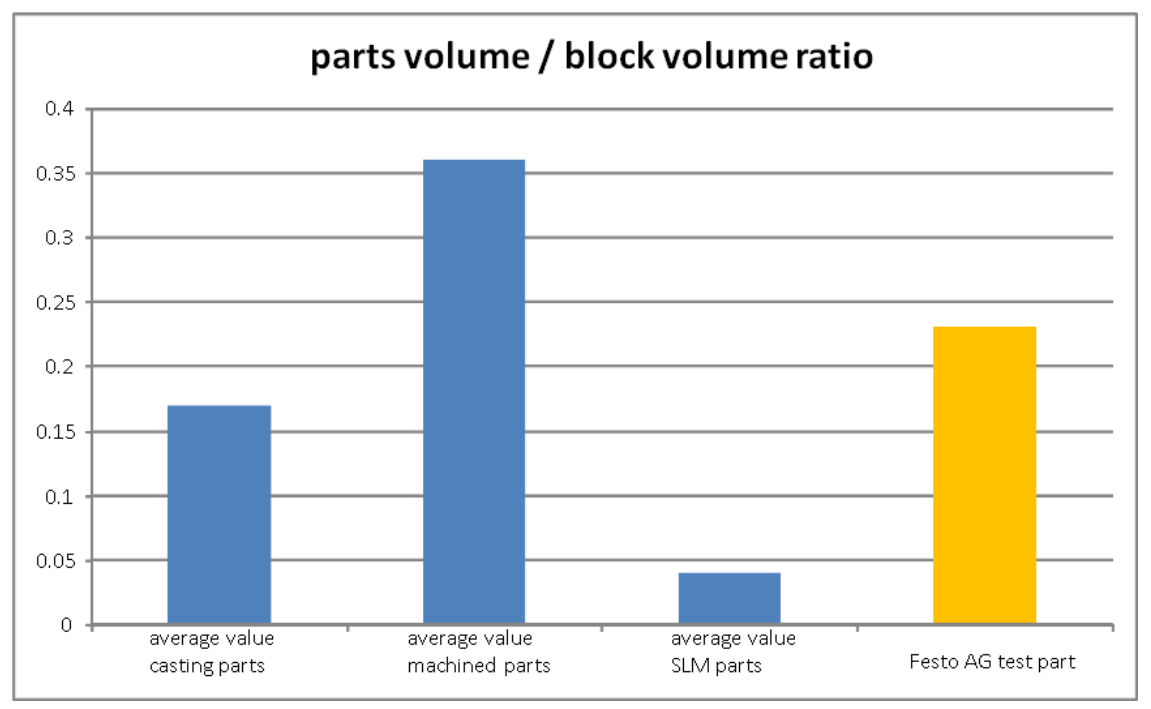

Figure 8: Complexity analysis based on parts volume/block volume ratio

All in all, the geometric complexity analysis of the three ratios as part of the ITEM indicates a medium-high to high geometric complexity of the Festo test part. The analysis suggests that the part is suitable for economic manufacturing by SLM. 


\section{CONCLUSION AND OUTLOOK}

Specific cost drivers of manufacturing processes are mainly influenced by the geometric complexity of the product. The complexity analysis presented here as part of the ITEM helps to determine geometric complexity, and supports the selection of a suitable manufacturing process. In general, highly complex products have low ratios of volume/number_of facets, parts volume/surface area, and parts volume/block volume, and are more suitab̄le for SLM. Products can be grouped by comparing their ratios with the average ratio values of the production technology groups (casting, machining, and SLM). In addition to the complexity analysis, a technical and economic analysis (included in the ITEM) is necessary to make an overall decision regarding the best manufacturing process.

Geometric complexity analysis allows several assumptions to be made, which are summarised in the following way. Besides the well-known advantages of the design flexibility of SLM, functional integration can lead to significant improvements in company operations. The idea of 'complexity for free' illustrates the possibility of integrating additional features in products to improve product performance at the same costs (see economic potential analysis on Level 3 of ITEM). According to the well-known Kano model, SLM gives additional space to integrating excitement factors, thus improving product performance and customer satisfaction. Functional optimised designs and more individualised designs follow this idea to better fulfil market demands. Figure 9 summarises the economic leverage effect of SLM in the three dimensions of cost, time, and quality enabled by the possibility of integrating 'additional complexity' (e.g. functional integration) into product designs. These leverage effects significantly reduce process complexity.

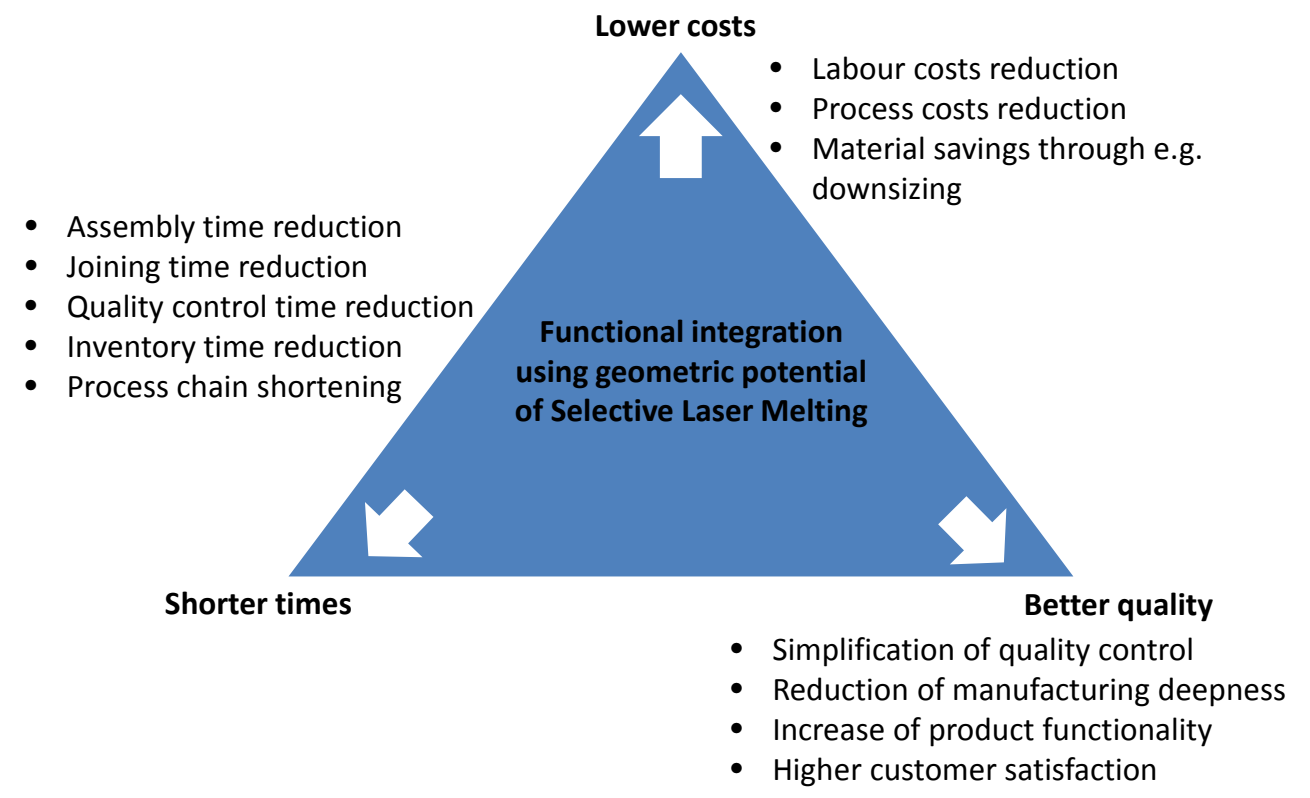

Figure 9: Economic levers through functional integration by SLM

The complexity analysis of a test part as presented here can be used as a starting point for more detailed complexity analysis. Key indicators like parts volume/number_of facets, parts volume/surface area, and parts volume/ block volume need to be extende $\bar{d}$ to obtain a comprehensive overview of product complexity. The geometric complexity of product design is dependent upon the chosen manufacturing process, and single geometric features can boost geometric complexity dramatically.

For casting processes, undercuts result in high geometric complexity, although they can be manufactured easily by SLM. Even when most of the product geometry contains simple 
geometric features, single features can cause maj or problems due to individual restrictions of the manufacturing processes. These individual restrictions need to be considered when evaluating the specific geometric complexity for a manufacturing process. For conventional manufacturing techniques, there is good evidence about geometric design restrictions, and design engineers use this information to develop their products. Although in the past few years great efforts have been made to develop 'design for additive manufacturing' practices, there is still no comprehensive collection of design rules for SLM. As a consequence, only manufacturing engineers experienced in using SLM are able to use its technological potential to the full.

Feature-based recognition systems are used to determine the manufacturing costs for machining [17]. Recognition systems are able to detect geometric features including feature properties (e.g. surface requirements). These feature-based recognition systems can be used to determine geometric complexity automatically, by detecting specific geometric cost drivers related to the manufacturing process. A better understanding of geometric complexity - and how it relates to different manufacturing processes - can be improved by these systems in future investigations.

\section{ACKNOWLEDGEMENTS}

The authors would like to thank the German Research Foundation (DFG) for supporting this research within the Cluster of Excellence 'Integrative Production Technology for High-Wage Countries'.

\section{REFERENCES}

[1] Meiners, W. 1999. Direktes Selektives Laser Sintern einkomponentiger metallischer Werkstoffe. Shaker Verlag Aachen.

[2] Wohlers, T. 2010. Wohlers Report 2010. Wohlers Associates.

[3] Gebhardt, A. 2007. Generative Fertigungsverfahren. Carl Hanser Verlag.

[4] Gibson, I., Rosen, D.W. \& Stucker, B. 2010. Additive manufacturing technologies. Springer Verlag.

[5] Schleifenbaum, H., Meiners, W., Wissenbach, K. \& Hinke, C. 2010. Individualized production by means of high power Selective Laser Melting. CIRP Journal of Manufacturing Science and Technology (2), 161-169.

[6] Buchbinder, D. 2011. High power selective laser melting (HP SLM) of aluminum parts. LIM Proceedings. Munich

[7] Levy, G.N. 2003. Rapid manufacturing and rapid tooling with layer manufacturing (LM) Technologies, state of the art and future perspectives. Annals of the CIRP, 52(2).

[8] Wiendahl, H.-H., Rempp, B. \& Schanz, M. 2000. Turbulenzen erschweren Planungssicherheit. IOManagement, 69, 38-43.

[9] Wegener, K. 2010. Vorwort 'Additive Fertigung'. SWISS RaPiD Forum, St. Gallen.

[10] Kröll, M. 2007. Methode zur Technologiebewertung für eine ergebnisorientierte Produktentwicklung. Dissertation, Universität Stuttgart, J ost-J etter Verlag Heimsheim.

[11] Bilsing A.P. 2007. Kennzahlengestützte Bewertung der technologischen Leistungs-fähigkeit der Fertigung im Werkzeug- und Formenbau. Dissertation, RWTH Aachen, Shaker Verlag.

[12] Voswinckel H. 2011. Design for manufacture based on an integrated product process design model, Key Engineering Materials, 473, 799-806.

[13] Zäh, M. 2006. Wirtschaftliche Fertigung mit Rapid-Technologien. Carl Hanser Verlag GmbH \& Co. KG; Auflage: 1.

[14] Valentan, B. 2008. Basic solutions on shape complexity evaluation of STL data. Journal of Achievements in Materials and Manufacturing Engineering, 26 (1).

[15] Valentan, B. 2006. Evaluation of shape complexity based on STL data. J ournal of Achievements in Materials and Manufacturing Engineering, 17 (1-2).

[16] Shah, J.J. 1992. Features in design and manufacturing: Intelligent design and manufacturing. J ohn Wiley \& Sons, Inc.

[17] Nagarajan, S. \& Venkata Reedy, N. 2010. Step-based automatic system for recognising design and manufacturing features. International J ournal for Production Research, 48 (1), 117-144. 